\section{FRI0077 DURABILITY AND RAPIDITY OF RESPONSE FOR RHEUMATOID ARTHRITIS PATIENTS RECEIVING THERAPY WITH ANAKINRA (IL-1RA)}

${ }^{1} \mathrm{DM}$ Miller, ${ }^{1} \mathrm{E}$ Ng, ${ }^{2} \mathrm{MH}$ Schiff, ${ }^{3} \mathrm{SB}$ Cohen, ${ }^{4} \mathrm{~B}$ Bresnihan. ${ }^{1}$ Development, Amgen, Thousand Oaks; ${ }^{2}$ Development, Denver Arthritis Clinic, Denver; ${ }^{3}$ Development, Metroplex Clinical Research Center, Dallas, USA; ${ }^{4}$ Development, St. Vincents University Hospital, Dublin, Ireland

\subsection{6/annrheumdis-2001.1206}

Background Anakinra (r-metHuIL-1ra) has been shown to be an effective therapy for Rheumatoid Arthritis patients since it improves the signs and symptoms of disease, as measured by ACR criteria. To better characterise this response, we have analysed data from two large, placebo controlled studies of anakinra, given as either monotherapy (MONO) or in combination with methotrexate (MTX).

Objectives

Methods To assess the ACR20 response over the time course of the studies, we evaluated the proportion of patients who had a sustained ACR20 response (Sus Resp), defined as at least four ACR20 responses by week 24, with at least one of the ACR20 responses occurring at either week 12 or 24.

Results Patients receiving anakinra doses $>1 \mathrm{mg} / \mathrm{kg}$ were 2-3 times more likely than placebo patients to achieve a sustained ACR. The sustained response for both studies was statistically significant. We also evaluated the rapidity of response to anakinra at these doses $(>1 \mathrm{mg} / \mathrm{kg}$ ). At least $50 \%$ of the subjects responding to anakinra achieved an ACR20 response on or before week 4 for either study.

\begin{tabular}{|c|c|c|c|c|c|c|}
\hline & Placebo & $\begin{array}{l}75 \mathrm{mg} \\
\text { anakinra }\end{array}$ & $\begin{array}{l}150 \mathrm{mg} \\
\text { anakinra }\end{array}$ & $\begin{array}{l}\text { Placebo } \\
+ \text { MTX }\end{array}$ & $\begin{array}{l}1 \mathrm{mg} / \mathrm{kg} \\
\text { anakinra } \\
+\mathrm{MTX}\end{array}$ & $\begin{array}{l}2 \mathrm{mg} / \mathrm{kg} \\
\text { anakinra } \\
+\mathrm{MTX}\end{array}$ \\
\hline$N$ & 121 & 116 & 116 & 48 & 59 & 46 \\
\hline $\begin{array}{l}\text { Sus } \\
(\%)\end{array}$ & $\begin{array}{l}13 \\
(10.7)\end{array}$ & $33(28.4)$ & $28(24.1)$ & $7(14.6)$ & $18(30.5)$ & $16(34.8)$ \\
\hline $\begin{array}{l}p- \\
\text { value }\end{array}$ & & 0.001 & 0.008 & & 0.039 & 0.013 \\
\hline
\end{tabular}

Conclusion In conclusion, treatment of RA patients with anakinra appears to produce a durable response with a quick onset of action. These factors support the use of anakinra as an effective therapy for rheumatoid arthritis.

\section{FRI0078 LONG TERM RESULTS OF YTTRIUM-90 RADIOSYNOVIORTHESIS IN CHRONIC KNEE SYNOVITIS OF DIFFERENT ORIGIN}

M Szentesi, S Takács. Department of Rheumatology, Semmelweis University of Budapest, Budapest, Hungary

\subsection{6/annrheumdis-2001.1207}

\section{Background}

Objectives Authors report on the results of Yttrium-90 radiosynoviorthesis in chronic synovitis of the knee joint. Out of these 213 patients 122 suffered from rheumatoid arthritis, 17 ankylosing spondylitis, 13 other seronegative spondylarthritis, 48 suffered from inflamed osteoarthritis, 1 hydrops articulorum intermitterns, 1 synovitis villonodularis, 11 from chronic traumatic synovitis.

Methods Evaulation was based on the criteria as described by Müller, Rau and Scütte the score system was developed by the authors.

Results In the first seven years excellent and good results were recorded in $71 \%$. They achieved excellent as well as good results at $83 \%$ of patients with rheumatoid arthritis, at $50 \%$ of patients with ankylosing spondylitis and at $55 \%$ of patients with osteoarthritis. Seven years after radiosynoviorthesis $65 \%$ of patients did not need another punction.

Conclusion Radiosynoviorthesis is as effective method of treating chronic synovitis as surgical synovectomy. The treatment must be done in rheumatoid arthritis Steinbrocker stadium I-II, local stadium I-II.

\section{FRI0079 ENBREL ${ }^{\circledR}$ (ETANERCEPT) IN ADDITION TO METHOTREXATE (MTX) IN RHEUMATOID ARTHRITIS (RA): LONG-TERM OBSERVATIONS}

${ }^{1}$ RM Fleischmann, ${ }^{2} \mathrm{ME}$ Weinblatt, ${ }^{3} \mathrm{MM}$ Kremer, ${ }^{4} \mathrm{AD}$ Bankhurst, ${ }^{5} \mathrm{KJ}$ Bulpitt, ${ }^{6} \mathrm{DJ}$ Burge. ${ }^{1}$ Rheumatology Associates, Metroplex Clinical Research Center, Dallas; ${ }^{2}$ Brigham and Women's Hospital, Boston; ${ }^{3}$ Albany Medical College, New York; ${ }^{4}$ University of New Mexico, Albuquerque; ${ }^{5}$ University of California, Los Angeles; ${ }^{6}$ Immunex Corporation, Seattle, USA

\subsection{6/annrheumdis-2001.1208}

Background Results have been previously presented from a longterm trial of ENBREL as additional therapy in 79 patients with persistent RA despite treatment with MTX. Patients have now received therapy for a median of 32 months (max. 37).

Objectives Continue to observe the safety and clinical benefit of ENBREL plus MTX.

Methods Disease activity was evaluated using ACR criteria. Adverse events were compared with data from a previous controlled study.

Results Of the 79 patients who entered the long-term trial, 9 have withdrawn: 3 for lack of efficacy, 2 for adverse events, 1 prior to a total knee replacement, 2 who planned to conceive, and 1 who started taking commercial ENBREL. Seventy of the 79 patients who entered the long-term study remain on therapy. No differences have been seen in the type and rate of adverse events observed over time, compared to the earlier controlled study. In the initial 6-month blinded study of ENBREL plus MTX, 2/59 patients were hospitalised for infections; in the extension study, 2/79 patients had a similar event. One patient developed NHL of the parotid gland in the initial study. In the extension study, two patients developed malignancies (squamous cell carcinoma of the larynx and breast carcinoma). Both of these patients in the extension study recovered and have resumed treatment with ENBREL. At baseline, all 79 patients were taking MTX and the mean dose was $18 \mathrm{mg}$. As allowed by the protocol, $54(68 \%)$ patients have reduced their MTX dose by a mean of $63 \%$, and $22 / 79$ (28\%) patients have discontinued taking MTX. In the 45 patients taking corticosteroids, the mean dose of prednisone was $6.3 \mathrm{mg}$. As allowed by the protocol, 30 (67\%) patients have reduced their steroid dose by a mean of $78 \%$, and 19 (42\%) patients have discontinued steroids. Improvement of disease activity has been sustained even though MTX and steroids were reduced or discontinued. At the most recent visit, $69 \%$ of patients had achieved the ACR 20,51\% the ACR 50, and 27\% the ACR 70. Also at the most recent visit, 19 patients had no tender joints, 10 had no swollen joints, and a zero HAQ score was achieved by 12 patients. 
Conclusion ENBREL plus MTX remains safe and well tolerated. Improvement of disease activity is sustained even with reduced or discontinued doses of MTX and/or steroids.

\section{REFERENCES}

1 Kremer JM, et al. Arthritis Rheum. 2000;43:S270

2 Weinblatt ME, et al. NEJM 1999;340:253-9

\section{FRI0080 LONG-TERM USE OF ENBREL ${ }^{\circledR}$ (ETANERCEPT) IN PATIENTS WITH DMARD-REFRACTORY RHEUMATOID ARTHRITIS}

${ }^{1}$ LW Moreland, ${ }^{2} \mathrm{SB}$ Cohen, ${ }^{3} \mathrm{SW}$ Baumgartner, ${ }^{4} \mathrm{MH}$ Schift, ${ }^{5} \mathrm{EA}$ Tindall, ${ }^{6} \mathrm{DJ}$ Burge. ${ }^{1}$ Division of Rheumatology, University of Alabama, Birmingham; ${ }^{2}$ Clinical Rheumatology, Metroplex Clinical Research Centre, Dallas, TX; ${ }^{3}$ Clinical Rheumatology, Physician's Clinic of Spokane, Spokane, WA; ${ }^{4}$ Clinical Rheumatology, Denver Arthritis Clinic, Denver, CO; ${ }^{5}$ Clinical Rheumatology, Portland Medical Associates, Portland, OR; ${ }^{6}$ Clinical Development, Immunex Corp., Seattle, WA, USA

10.1136/annrheumdis-2001.1209

Background Results have been previously presented from a longterm safety trial of ENBREL as monotherapy in adult patients with RA who had failed at least one DMARD. In this ongoing study, 628 patients have been followed for up to 4.3 years (median $=2.4$ years) for a total of 1336 patient-years.

Objectives Continue to observe the long-term safety and clinical benefit of ENBREL.

Methods Patients were evaluated for disease activity using ACR criteria. Adverse event rates were compared with data from controlled studies.

Results 479 adult patients have received ENBREL as monotherapy for over 1 year, 420 for over 2 years, 164 for over 3 years, and 12 for over 4 years. Response has been sustained for the duration of therapy. At baseline, the median tender joint count was 31 and the median swollen joint count was 25 . At 3.5 years, the median tender and swollen joint counts were 3 each, and $69 \%$ of patients had achieved the ACR 20,50\% the ACR 50, and $25 \%$ the ACR 70 . Also at 3.5 years, $24 \%$ of patients had zero tender joints, $26 \%$ had zero swollen joints, and $15 \%$ had disability scores of zero. In addition, 59\% of patients who were receiving corticosteroids at study start have decreased their steroid doses by a mean of $71 \%, 29 \%$ of patients have completely discontinued steroids, and only 5\% have increased their steroid dose. Compared to events seen in controlled trials or in the normal adult population, no significant differences in rate or type of adverse events were seen in patients treated with ENBREL over time. Serious adverse events occurred at a rate of 0.13 per patient-year in the long-term database compared to 0.13 in ENBREL-treated patients and 0.20 in placebo patients in the controlled studies. Likewise, serious infections (associated with hospitalisation or IV antibiotics) occurred at a rate of 0.05 per patient-year in the long-term database compared to 0.04 in ENBREL patients and 0.05 in placebo patients in the controlled studies. The number of malignancies reported in ENBREL patients was similar to the expected number calculated from the National Cancer Institute SEER database (9 reported vs. 12.7 expected). No opportunistic infections have been observed.

Conclusion ENBREL as monotherapy continues to be safe and effective in patients with DMARD-refractory RA for over 4 years.

\section{REFERENCE}

1 Moreland LW, et al. Arthritis Rheum. 2000;43:S270

\section{FRI0081 IMPROVEMENT OF DISABILITY IN RA PATIENTS WITH EARLY VS ESTABLISHED DISEASE AFTER TREATMENT WITH ENBREL ${ }^{\circledR}$ (ETANERCEPT)}

${ }^{1} \mathrm{R}$ Fleischmann, ${ }^{2} \mathrm{~S}$ Baumgartner, ${ }^{3} \mathrm{~L}$ Moreland, ${ }^{4} \mathrm{M}$ Schiff, ${ }^{5} \mathrm{~J}$ Markenson, ${ }^{6} \mathrm{G}$ Spencer-Green. ${ }^{1}$ Rheumatology Associates, Metroplex Clinical Research Center, Dallas, $T X_{;}{ }^{2}$ Clinical Rheumatology, Physician's Clinic of Spokane, Spokane, WA; ${ }^{3}$ Division Clinical Immunology and Rheumatology, University of Alabama, Birmingham, AL; ${ }^{4}$ Clinical Rheumatology, Denver Arthritis Clinic, Denver, CO; ${ }^{5}$ Department of Medicine-Rheumatology, Hospital for Special Surgery, New York, NY; ${ }^{6}$ Clinical Development, Immunex Corp., Seattle, WA, USA

10.1136/annrheumdis-2001.1210

Background Functional health status declines and disability increases early in patients with RA, with half of affected patients developing moderate loss of functional ability within 2 years of diagnosis. ${ }^{1}$ Early initiation of aggressive treatment has been suggested as a means to improve long-term outcomes.

Objectives To evaluate the impact of early therapy with ENBREL on disability.

Methods In this analysis, we compared the improvement in Health Assessment Questionnaire (HAQ) disability scores over 2 years in 207 patients with early disease (mean duration of RA was 1 year) to 563 patients with long-standing disease (mean duration of RA 12 years) who were treated with $25 \mathrm{mg}$ ENBREL SC twice weekly.

Mean baseline patient characteristics in the early vs. late groups were similar, including HAQ (1.5 vs 1.6$)$, number of tender (31 vs 32 ) and swollen ( 24 vs 26 ) joints, CRP (3.3 vs 4.4 $\mathrm{mg} / \mathrm{dL}$ ), presence of RF ( $87 \%$ vs $81 \%$ ), and age (51 vs 53 years). Patients with early disease had been treated with fewer DMARDS (0.5 vs 3.3 ).

Results Patients with both early and late RA achieved rapid and sustained clinical responses and improvement in HAQ scores, but the magnitude of improvement in HAQ was greater in patients with early disease. At 2 years, mean HAQ scores declined from 1.5 to 0.6 in the early RA group and from 1.6 to 1.0 in patients with established disease. The proportion of patients who achieved zero HAQ scores was greater for patients with early disease (29\%) compared to patients with late disease $(14 \%)(\mathrm{p}<0.001)$.

Conclusion While patients with early or long-standing disease had significant improvement in disability with ENBREL therapy, patients with early disease had greater benefit. Aggressive therapy in patients with early RA has greater potential to improve disability as measured by HAQ than in patients with more established disease who have failed multiple DMARDs.

\section{REFERENCE}

1 Wolfe F. A Reappraisal of HAQ disability in rheumatoid arthritis. Arthritis Rheum. 2000;43:2751-61

\section{FRI0082 EFFECT OF HYDROXYCHLOROQUINE THERAPY ON CARTILAGE INJURY IN RHEUMATOID ARTHRITIS}

HB Lindsley, D Eyre, L Atley, DD Smith. Internal Medicine, University of Kansas Medical Center, Kansas City, USA

10.1136/annrheumdis-2001.1211

Background Better methods for assessing articular injury are needed to monitor efficacy of disease-modifying therapy in rheumatoid arthritis (RA).

Objectives The purpose of this study was to measure serum levels of cross-linked peptides from the C-telopeptide of type II collagen $\left(\mathrm{col}^{2} \mathrm{CTx}\right)$ during treatment of patients with RA. 